\title{
Roles of CREB in the regulation of FMRP by group I metabotropic glutamate receptors in cingulate cortex
}

\author{
Hansen Wang ${ }^{1}$, Yoshikazu Morishita ${ }^{2}$, Daiki Miura², Jose R Naranjo ${ }^{3}$, Satoshi Kida ${ }^{2}$ and Min Zhuo ${ }^{1,4,5^{*}}$
}

\begin{abstract}
Background: Fragile $X$ syndrome is caused by lack of fragile $X$ mental retardation protein (FMRP) due to silencing of the FMR1 gene. The metabotropic glutamate receptors (mGluRs) in the central nervous system contribute to higher brain functions including learning/memory, mental disorders and persistent pain. The transcription factor cyclic AMP-responsive element binding protein (CREB) is involved in important neuronal functions, such as synaptic plasticity and neuronal survival. Our recent study has shown that stimulation of Group I mGluRs upregulated FMRP and activated CREB in anterior cingulate cortex (ACC), a key region for brain cognitive and executive functions, suggesting that activation of Group I mGluRs may upregulate FMRP through CREB signaling pathway.

Results: In this study, we demonstrate that CREB contributes to the regulation of FMRP by Group I mGluRs. In ACC neurons of adult mice overexpressing dominant active CREB mutant, the upregulation of FMRP by stimulating Group I mGluR is enhanced compared to wild-type mice. However, the regulation of FMRP by Group I mGluRs is not altered by overexpression of $\mathrm{Ca}^{2+}$-insensitive mutant form of downstream regulatory element antagonist modulator (DREAM), a transcriptional repressor involved in synaptic transmission and plasticity.
\end{abstract}

Conclusion: Our study has provided further evidence for CREB involvement in regulation of FMRP by Group I mGluRs in ACC neurons, and may help to elucidate the pathogenesis of fragile $X$ syndrome.

Keywords: CREB, FMRP, Group I mGluRs, Gene expression, Cingulate cortex, Fragile X syndrome

\section{Background}

Fragile $\mathrm{X}$ syndrome, the most common cause of inherited mental retardation and autism spectrum disorders, is caused by mutations of the FMR1 gene that encodes the fragile $\mathrm{X}$ mental retardation protein (FMRP) [1-9]. FMRP, an mRNA binding protein, is involved in activitydependent synaptic plasticity through regulation of local protein synthesis at synapses [2,7,9-16]. It normally functions as a repressor of translation of specific mRNAs [10,15,17-19]. The abnormal functions of Group I mGluR-dependent synaptic plasticity have been observed in hippocampus of Fmr1 knockout (KO) mice $[16,17,20-23]$. It is believed that the protein synthesis

\footnotetext{
* Correspondence: min.zhuo@utoronto.ca

'Department of Physiology, Faculty of Medicine, University of Toronto,

1 King's College Circle, Toronto, ON M5S 1A8, Canada

${ }^{4}$ Center for Neuron and Disease, Frontier Institute of Science and

Technology, Xi'an Jiaotong University, Xi'an, China

Full list of author information is available at the end of the article
}

downstream of Group I mGluRs are exaggerated due to the lack of FMRP in fragile $X$ syndrome $[8,17,21,24]$.

The anterior cingulate cortex (ACC) is important for cognitive learning, fear memory and persistent pain [2531]. Previous studies have shown that trace fear memory is impaired in Fmr1 KO mice, accompanied by alterations in synaptic plasticity in ACC, suggesting that the dysfunction of ACC due to lack of FMRP may be responsible for certain types of mental disorders in fragile $\mathrm{X}$ syndrome $[27,32]$. The mGluRs in ACC contribute to activitydependent synaptic plasticity and behavioral fear memory $[33,34]$. The regulation of FMRP by mGluRs has been mostly studied in hippocampal neurons $[11,17,21,35,36]$. Our recent study has found that activation of Group I mGluRs regulates the expression of FMRP in ACC neurons and activates cyclic AMP-responsive element binding protein (CREB) [37,38], a transcriptional factor which plays many functional roles in central nervous system, such as neuronal survival, synaptic plasticity, learning and 
memory [39-45]. These findings indicate possible roles of CREB in linking mGluRs to FMRP in ACC. Loss of this signaling pathway may contribute to the pathogenesis of fragile X syndrome.

In the present study, we have demonstrated that CREB is involved in the regulation of FMRP by Group I mGluRs. In cingulate cortex from transgenic mice overexpressing dominant active CREB (Y134F) mutant which displays a higher affinity with cAMP dependent kinase (PKA) compared to wild-type (WT) CREB [46,47], we found the upregulation of FMRP by stimulating Group I mGluR was enhanced compared to that of WT mice. By contrast, the regulation of FMRP by Group I mGluRs was not affected by overexpression of $\mathrm{Ca}^{2+}$ insentive mutant form of downstream regulatory element antagonist modulator (DREAM), a transcriptional repressor involved in synaptic plasticity, learning and memory [48-50]. We propose that CREB is the key transcription factor in regulation of FMRP by Group I mGluRs in ACC neurons.

\section{Results}

Overexpression of dominant active CREB enhances the regulation of FMRP by group I mGluRs in the ACC neurons

Phosphorylated CREB (pCREB) binds to cAMP response element (CRE) site in gene promoters and activates gene transcription $[41,42,45,51,52]$. It has been reported that the $F M R 1$ gene promoter contains the CRE site $[53,54]$. Our recent study had found that (RS)-3, 5-Dihydroxyphenylglycine ((RS)-3, 5-DHPG) treatment could upregulate FMRP and increase the pCREB levels in ACC slices, suggesting that the regulation of FMRP by Group I mGluRs in ACC neurons likely occurs through CREB activation $[37,38]$.

Overexpression of dominant active CREB mutant in the forebrain could positively regulate memory consolidation and enhance memory performance by upregulating the expression of Brain derived neurotrophic factor (BDNF) [47], which is well known as a CREB target gene $[40,42,55]$. To further investigate whether CREB is involved in the upregulation of FMRP caused by stimulating Group I mGluRs, we then tested the expression of FMRP induced by the Group I mGluR agonist DHPG $(100 \mu \mathrm{M}, 30 \mathrm{~min})$ treatment in ACC slices from mice overexpressing CREB. By Western blot, we found that there was no difference in the basal levels of FMRP in ACC slices between WT and CREB overexpression mice $(P>0.05$, compared with WT mice, $n=5$, Figure $1 \mathrm{~A})$. DHPG treatment could increase expression of FMRP in ACC slices; the increase of FMRP was further enhanced in ACC slices from mice overexpressing CREB compared to WT mice $(198 \pm 11 \%$ and $248 \pm 14 \%$ of the WT control levels for WT and CREB overexpression mice, respectively. In two-way ANOVA analysis, for genotype,
$F=13.39, \quad P<0.01 ;$ for treatment, $F=254.87, \quad P<0.01$; genotype $\mathrm{X}$ treatment, $F=8.26, P<0.05 ; n=5$ for each group, Figure $1 \mathrm{~B})$. The data indicates that overexpression of CREB can enhance the upregulation of FMRP induced by Group I mGluR activation. It provides further evidence that CREB is involved in the regulation of FMRP by Group I mGluRs in ACC neurons.

\section{Overexpression of $\mathrm{Ca}^{2+}$-insensitive DREAM does not affect the regulation of FMRP by group I mGluRs in the ACC neurons}

Since transcriptional repressor DREAM interacts with CREB in a $\mathrm{Ca}^{2+}$ dependent manner and prevents the recruitment of CREB-binding protein (CBP) blocking CRE-dependent gene transcription $[48,56]$, we next checked whether DREAM might be involved in the regulation of FMRP by Group I mGluRs through CREB signaling pathway. To explore the role of DREAM in the upregulation of FMRP by stimulating Group I mGluRs, we have taken the advantage of transgenic mice overexpressing a $\mathrm{Ca}^{2+}$-insensitive DREAM mutant (TgDREAM) [49,50]. The TgDREAM mice could develop normally and did not exhibit any abnormalities in brain structures. However, overexpression of mutant DREAM impaired NMDA receptor-mediated synaptic plasticity and contextual fear memory [50].

We next tested the effect of DHPG $(100 \mu \mathrm{M}, 30 \mathrm{~min})$ treatment in ACC slices from TgDREAM mice. Importantly, no difference in the basal levels of FMRP in ACC slices was observed between WT and TgDREAM mice $(\mathrm{P}>0.05$, compared with WT mice, $\mathrm{n}=5$, Figure $1 \mathrm{C})$. Furthermore, the increase of FMRP after DHPG treatment was not affected in ACC slices from TgDREAM mice compared to WT mice $(199 \pm 10 \%$ and $201 \pm 9 \%$ of the WT control levels for WT and TgDREAM mice, respectively. In two-way ANOVA analysis, for genotype, $F=0.10, P=0.75$; for treatment, $F=249.81, P<0.01$; for genotype $\mathrm{X}$ treatment, $F=0.001, P=1.00 ; n=5$ for each group, Figure 1D). The data indicate that overexpression of $\mathrm{Ca}^{2+}$-insensitive mutant form of DREAM does not affect the upregulation of FMRP induced by Group I mGluR activation, suggesting that DREAM might not be involved in the CREB-dependent regulation of FMRP by Group I mGluRs in ACC neurons.

\section{Putative CREs in the FMR1 promoter}

To identify conserved sequences, $20 \mathrm{~kb}$ of mouse genomic sequence including the FMR1 transcription start site (TSS) was aligned among multiple mammalian species using the UCSC Genome browser (Figure 2). Sequences of multiple mammalian species were then scanned for matches to the consensus sequence of CRE (TGACGTCA). Two putative CREs (upstream CRE, $-48 \sim-45$; downstream CRE, $+106 \sim+113$ ) were found in 


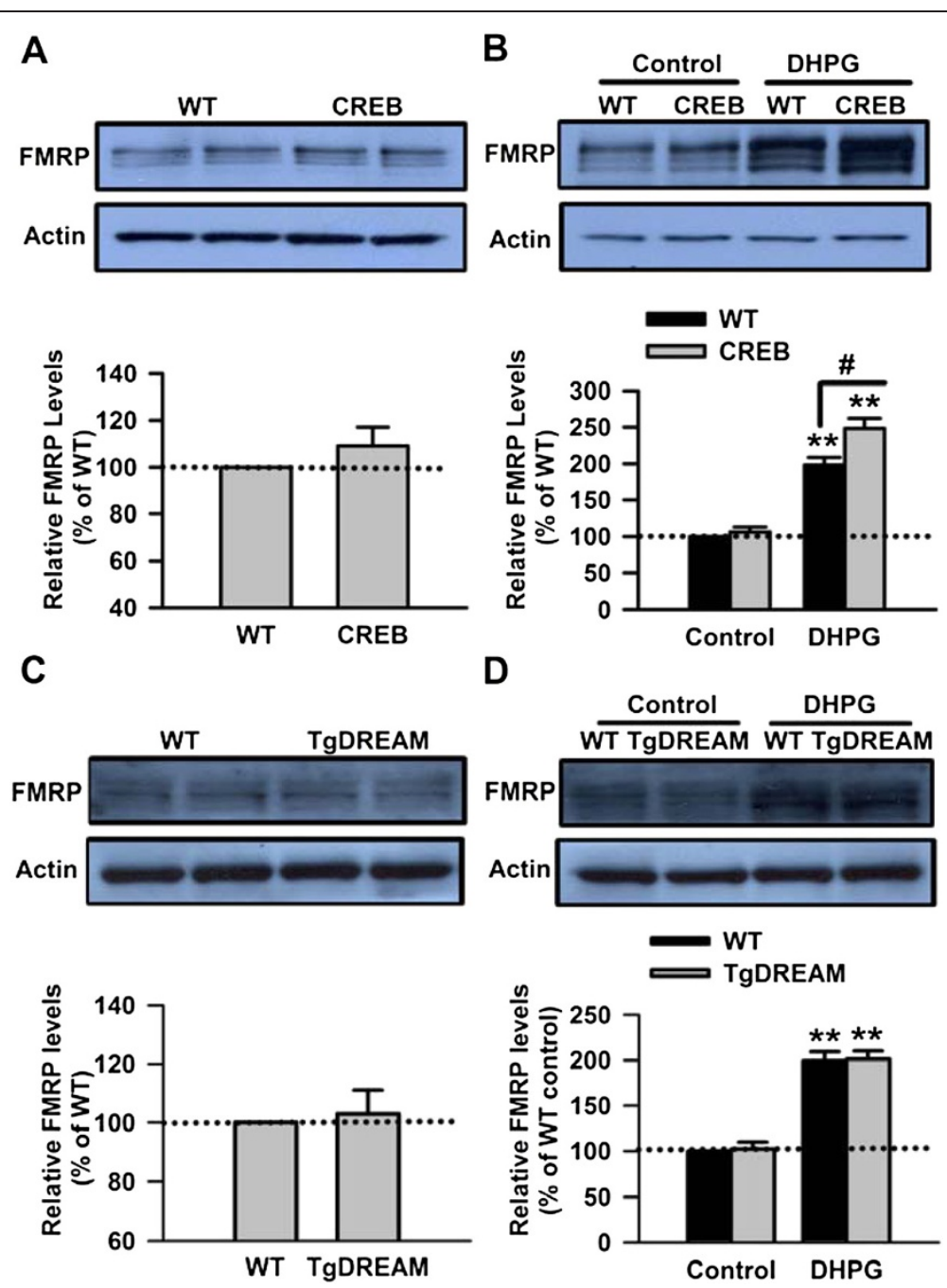

Figure 1 Upregulation of FMRP by Group I mGluRs was enhanced in ACC from CREB mutant mice, whereas it was not affected in transgenic mice overexpressing a $\mathrm{Ca}^{2+}$-insensitive DREAM mutant (TgDREAM). A, The basal levels of FMRP in ACC slices of CREB mutant mice were not affected. B, The increase of FMRP after treatment with Group I mGluR agonist DHPG (100 $\mu \mathrm{M})$ for 30 min, was enhanced in ACC slices from CREB mutant mice, as compared to wild-type (WT) mice. Representative Western blot (top) and quantification data (bottom) of FMRP are shown for the corresponding treatments. C, The basal levels of FMRP in ACC slices of TgDREAM mice were not affected. D, The increase of FMRP after treatment with Group I mGluR agonist DHPG $(100 \mu \mathrm{M})$ for 30 min, was not changed in ACC slices from TgDREAM mutant mice, as compared to wild-type (WT) mice. Representative Western blot (top) and quantification data (bottom) of FMRP are shown for the corresponding treatments. Data were normalized by WT control values. ${ }^{* *} P<0.01$, compared to control mice; \# $P<0.05$, compared to WT DHPG treatment. $n=5$ mice for each group.

the highly conserved regions across multiple mammals (Figure 2A). The upstream putative CRE has been reported as a potential CRE in human FMR1 promoter $[53,54]$. Comparisons of putative CRE sequences among mammalian species are shown in Figure 2B. These data support our finding that the FMR1 is a target gene of CREB.

\section{Discussion}

Our previous studies have shown that FMRP is required for the physiological function of ACC [25,27,57], the mGluRs in ACC may contribute to the activity- dependent synaptic plasticity and fear memory [33,34]. Recently, we have provided the direct biochemical evidence that activation of Group I mGluRs upregulates FMRP in ACC neurons of adult mice; the upregulation of FMRP by Group I mGluRs occurs at the transcriptional level, stimulation of Group I mGluRs induced the phosphorylation of CREB in ACC neurons [37,38]. In this study, we provided further evidence that CREB contributes to the upregulation of FMRP induced by stimulating Group I mGluRs and may act as a key signaling molecule linking Group I mGluRs and FMRP in cingulate cortex. 


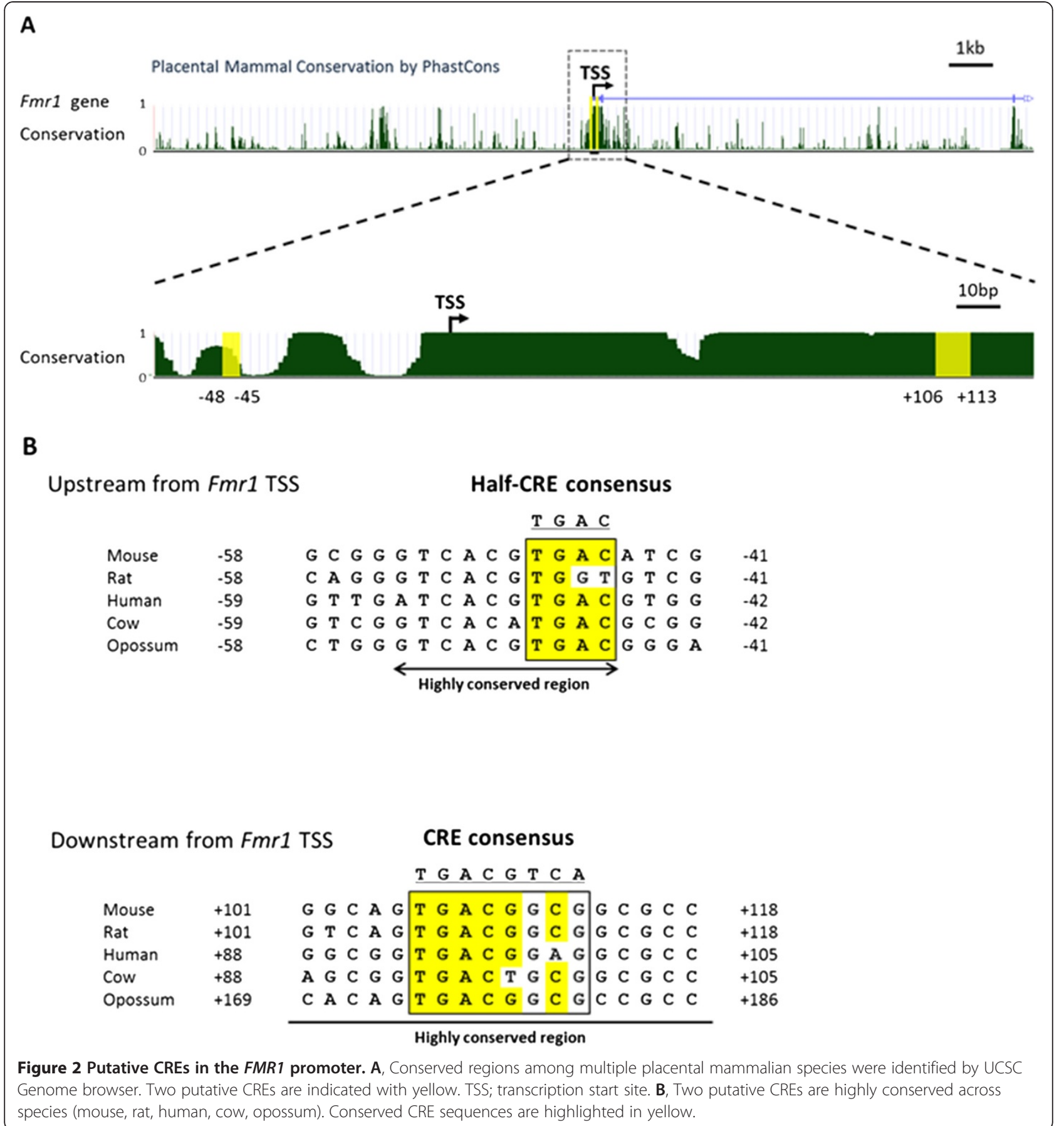

CREB is a transcriptional factor that plays important roles in synaptic plasticity [40-45,52]. The activity of CREB is regulated by its phosphorylation; pCREB binds to the CRE site within the gene and activates the gene transcription $[40,42,45,51,52]$. Previous and our current studies have shown that there is the CRE site in FMR1 promoter, and implicated CREB in the regulation of the FMR1 gene transcription in neural cells (Figure 2) [53,54]. Our recent studies found that the Group I mGluR activation upregulates
FMRP at the transcriptional level in ACC neurons; the upregulation of FMRP is accompanied by the phosphorylation of CREB (Ser133); $\mathrm{Ca}^{2+}$-stimulated adenylyl cyclase 1 (AC1), PKA and $\mathrm{Ca}^{2+} /$ Calmodulin-dependent protein kinase IV (CaMKIV) contribute to regulation of FMRP by Group I mGluR probably through CREB activation [37,38] (see Table 1). These findings supported that CREB acts as a transcriptional factor for Group I mGluR-dependent upregulation of FMRP in the ACC neurons. 
Table 1 Studies on signaling pathway of CREB activation by Group I mGluRs in cingulate cortex

\begin{tabular}{lllr}
\hline Signaling molecules & \multicolumn{1}{c}{ Manipulations } & Effects on CREB phosphorylation induced by DHPG & References \\
\hline AC1 & ACl knockout & Reduced & 38 \\
PKA & PKA inhibitor & Reduced & 38 \\
CaMKIV & CaMKIV knockout & Reduced & 38 \\
& CaMK inhibitor & Reduced & 37 \\
& CaMKIV over expression & Enhanced & 37 \\
\hline
\end{tabular}

In this study, we have shown that the upregulation of FMRP induced by Group I mGluR agonist DHPG DHPG is enhanced in ACC slices from mice overexpressing dominant active CREB (Y134F) mutant. This finding further supports that CREB is critical for the regulation of FMRP by Group I mGluRs in ACC neurons. We also found that overexpression of dominant active CREB mutant does not affect the basal levels of FMRP, although it enhanced the upregulation of FMRP by stimulating Group I mGluRs in ACC slices. These results may reflect less synaptic activity at baseline condition, or suggest that CREB, which can be shared by many different signaling pathways, may specifically contribute to the upregulation of FMRP by stimulating
Group I mGluRs (see Figure 3 for the model). It is possible that long term expression of dominant active CREB in the mice may cause some developmental or secondary changes in ACC of transgenic mice. However, we think that the effect of CREB mutant on regulation of FMRP by Group I mGluRs cannot be simply attributed to developmental or secondary changes in ACC since the roles of CREB have been further supported by other genetic and pharmacological evidence from our previous studies $[37,38]$.

DREAM, a multifunctional $\mathrm{Ca}^{2+}$-binding protein, contributes to synaptic plasticity, and behavioral learning and memory. As a transcriptional repressor, it can affect CRE-dependent gene transcription by preventing the

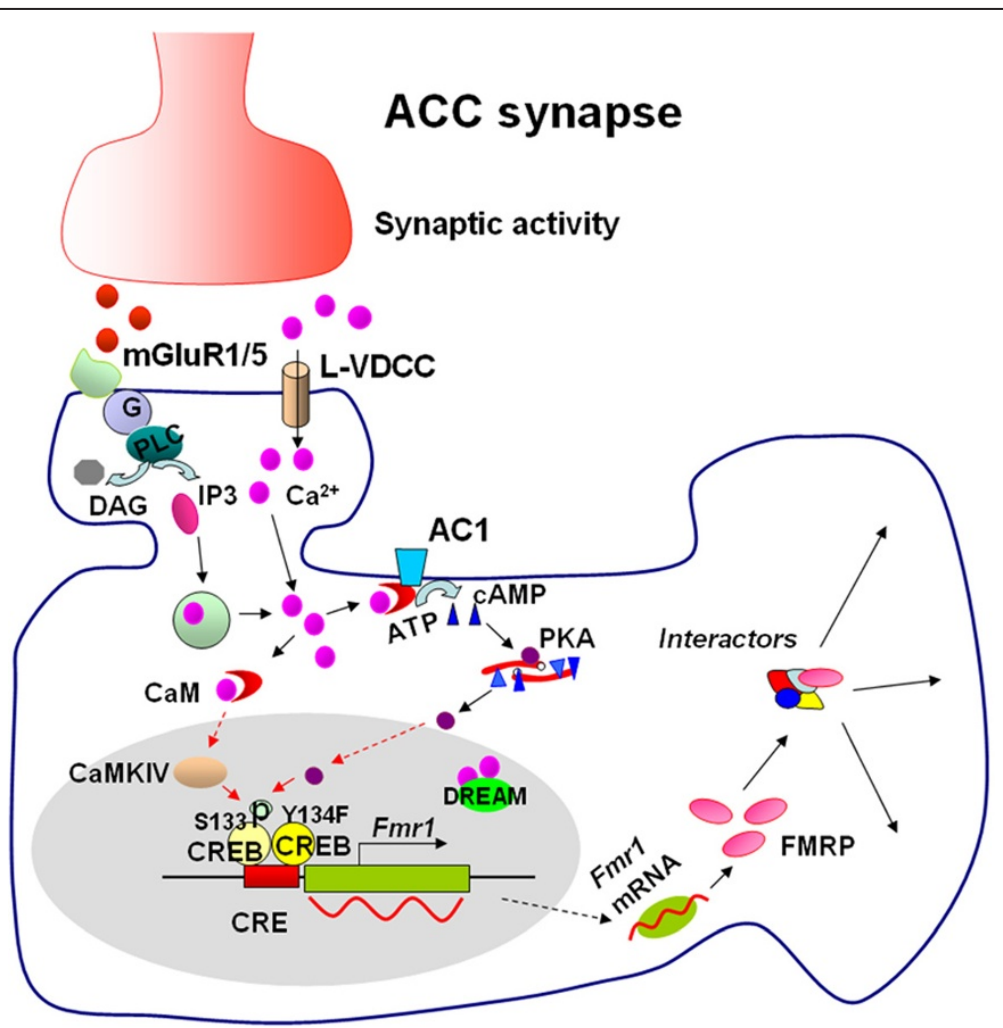

Figure 3 The signaling pathway for CREB in the regulation of FMRP by Group I mGluRs in ACC neurons. Stimulation of mGluR1/5 triggers the $\mathrm{Ca}^{2+}$ release from intracellular calcium stores by IP3 and $\mathrm{Ca}^{2+}$ influx from L-VDCCs through membrane depolarization. The increase of $\mathrm{Ca}^{2+}$ leads to activation of $\mathrm{Ca}^{2+}$-calmodulin (CaM) dependent pathways, including $\mathrm{Ca}^{2+}$ and $\mathrm{CaM}$ stimulated AC1-cAMP dependent protein kinase (PKA) and CaMKIV. PKA and CaMKIV then phosphorylates CREB. Phosphorylated CREB (pCREB) initiates the CREB-dependent transcription of Fmr1 gene and upregulates FMRP in the cytoplasm. The mutant CREB (Y134F) contributes to transcription of Fmr1 gene, whereas DREAM may not be involved in Fmrl gene expression. FMRP may interact with its interactors and modulate neuronal functions in ACC. 
recruitment of CBP by pCREB $[48,49,56]$. In this study, we found the upregulation of FMRP by stimulating Group I mGluRs was not affected in ACC slices from mice overexpressing $\mathrm{Ca}^{2+}$-insensitive mutant form of DREAM. The data indicates that overexpression of this mutant form of DREAM does not affect basal expression or CREB-dependent FMRP induction by Group I mGluRs. Since the overexpression of TgDREAM has been associated with the repression of different target genes $[49,58,59]$, these results suggest that DREAM might not be involved in the regulation of the FMRP in ACC neurons.

\section{Conclusion}

We have demonstrated that CREB is critical for regulation of FMRP by Group I mGluRs in ACC neurons by using genetic approaches. Our study has provided further evidence that CREB is involved in regulation of FMRP by Group I mGluRs in cingulate cortex, and may help to further elucidate the molecular and cellular mechanisms underlying fragile $\mathrm{X}$ syndrome.

\section{Materials and methods}

\section{Animals}

Adult male $\mathrm{C} 57 \mathrm{Bl} / 6$ mice were used in most of experiments. The transgenic mice overexpressing dominant active mutant CREB (Y134F) or $\mathrm{Ca}^{2+}$ insentive DREAM were generated and maintained as reported previously [47,50]. All mice were housed under a 12:12 light cycle with food and water provided ad libitum. All mouse protocols are in accordance with NIH guidelines and approved by the Animal Care and Use Committee of University of Toronto.

\section{Drugs and antibodies}

(RS)-3, 5-DHPG was purchased from Tocris Bioscience (Ellisville, MO). phosphatase inhibitor cocktail 1 and 2 were purchased from Sigma-Aldrich (St. Louis, MO). The anti-FMRP antibody, horseradish peroxidase-linked goat anti-mouse IgG and goat anti-rabbit IgG for Western blot were purchased from Chemicon International (Temecula, CA). The anti-phospho-threonine antibody, anti-CREB antibody and anti-phosph CREB antibody were purchased from Cell Signaling Technology (Danvers, MA). The anti-actin antibody was from SigmaAldrich (St. Louis, MO).

\section{Brain slice preparations}

Mice were anesthetized with $2 \%$ halothane and brain slices $(300 \mu \mathrm{m})$ containing ACC were cut at $4^{\circ} \mathrm{C}$ using a Vibratome, in oxygenated artificial cerebrospinal fluid [ACSF; containing the following (in $\mathrm{mM}$ ): $124 \mathrm{NaCl}, 4$ $\mathrm{KCl}, 26 \mathrm{NaHCO}_{3}, 2.0 \mathrm{CaCl}$, $1.0 \mathrm{MgSO}_{4}, 1.0 \mathrm{NaH}_{2} \mathrm{PO}_{4}$, $10 \mathrm{D}$-glucose, $\mathrm{pH}$ 7.4]. The slices were slowly brought to final temperature of $30^{\circ} \mathrm{C}$ in ACSF gassed with 95\% $\mathrm{O}_{2} / 5 \% \mathrm{CO}_{2}$ and incubated for at least 1 hour before experiments. Slices then were exposed to different compounds of interest for the indicated times and snap frozen over dry ice. For biochemical experiments, the ACC regions were microdissected and sonicated in icecold homogenization buffer containing phosphatase and protease inhibitors.

\section{Western blot analysis}

Western blot was conducted as previously described $[25,38]$. The brain tissues were dissected and homogenized in lysis buffer containing $10 \mathrm{mM}$ Tris- $\mathrm{HCl}(\mathrm{pH}$ 7.4), 2 mM EDTA, 1\% SDS, 1X protease inhibitor cocktail, and $1 \mathrm{X}$ phosphatase inhibitor cocktail 1 and 2. Protein concentration was measured by Bradford protein assay (Bio-Rad, Hercules, CA). Electrophoresis of equal amounts of total protein was performed on NuPAGE 412\% Bis-Tris Gels (Invitrogen, Carlsbad, CA). Separated proteins were transferred to polyvinylidene fluoride membranes (Pall Corporation, East Hills, NY) at $4^{\circ} \mathrm{C}$ for analysis. Membranes were probed with 1:3000 dilution of anti-FMRP, or 1:1000 dilution of anti-phospho-CREB (Ser133) and anti-CREB antibodies. The membranes were incubated in the appropriate horseradish peroxidasecoupled secondary antibody diluted 1:3000 for $2 \mathrm{~h}$ followed by enhanced chemiluminescence (ECL) detection of the proteins with Western Lightning Plus-ECL (PerkinElmer Life and Analytical Science Inc., Waltham, MA) according to the manufacturer's instructions. To verify equal loading, membranes were also probed with 1:3000 dilution of antiactin antibody. The density of immunoblots was measured using NIH ImageJ program.

\section{Data analysis}

All data were presented as the mean \pm S.E.M. Statistical comparisons were performed by paired $t$-test or two-way ANOVA. In all cases, $P<0.05$ is considered statistically significant.

\section{Abbreviations \\ FMRP: Fragile $X$ mental retardation protein; mGluRs: Metabotropic glutamate receptors; CaMKIV: $\mathrm{Ca}^{2+}$ /calmodulin-dependent protein kinase IV; \\ AC1: Adenylyl cyclase 1; ACC: Anterior cingulate cortex; DHPG: (RS)-3, 5- Dihydroxyphenylglycine; CREB: Cyclic AMP-responsive element binding protein; pCREB: Phosphorylated CREB; DREAM: Downstream regulatory element antagonist modulator; PKA: CAMP dependent kinase; WT: Wild-type.}

Competing interests

The authors declare that they have no competing interests.

\section{Authors' contributions}

Hansen Wang and Min Zhuo designed the study and wrote the manuscript Hansen Wang performed the experiments. Yoshikazu Morishita, Daiki Miura and Satoshi Kida provided the CREB mutant mice and analyzed CRE sequences in the FMR1 promoter. Jose R Naranjo provided the DREAM mutant mice. Min Zhuo supervised the study. All authors read and approved the final manuscript. 


\section{Acknowledgments}

This work was supported by grants from the EJLB-CIHR Michael Smith Chair in Neurosciences and Mental Health, Canada Research Chair, Canadian Institute for Health Research operating grant (MOP-124807), NSERC Discovery Grant (RGPIN 402555) (M. Z.). H. W. was supported by Postdoctoral Fellowship from The Fragile X Research Foundation of Canada. S. K. was supported by Grant-in-Aids for Scientific Research 20380078 and 20658035, and High Technology Research and Priority Areas (Molecular Brain Science) 18022038 and 20022039 from the Ministry of Education, Culture, Sports, Science, and Technology, Japan; Core Research for Evolutional Science and Technology, Japan; and the Research Grant for Nervous and Mental Disorders from the Ministry of Health, Labour, and Welfare, Japan; and grants ERA-Net Neuron (grant nEUROsyn 2008), Ministerio Ciencia e Innovacion (SAF2007-62449) and CIBERNED to J.R.N.

\section{Author details}

'Department of Physiology, Faculty of Medicine, University of Toronto, 1 King's College Circle, Toronto, ON M5S 1A8, Canada. ${ }^{2}$ Department of Bioscience, Faculty of Applied Bioscience, Tokyo University of Agriculture, Tokyo 156-8502, Japan. ${ }^{3}$ Centro Nacional de Biotecnologia, Consejo Superior de Investigaciones Científicas and Centro Investigaciones Biomedicas En Red-NEuroDegenerativas, E-28049 Madrid, Spain. ${ }^{4}$ Center for Neuron and Disease, Frontier Institute of Science and Technology, Xi'an Jiaotong University, Xi'an, China. ${ }^{5}$ Department of Physiology, University of Toronto, Faculty of Medicine, 1 King's College Circle, Toronto, ON M5S 1A8, Canada.

Received: 25 June 2012 Accepted: 2 August 2012

Published: 6 August 2012

\section{References}

1. Belmonte MK, Bourgeron T: Fragile $X$ syndrome and autism at the intersection of genetic and neural networks. Nat Neurosci 2006, 9(10):1221-1225.

2. Bhakar AL, Dolen G, Bear MF: The Pathophysiology of Fragile $X$ (and What It Teaches Us about Synapses). Annu Rev Neurosci 2012, 2012:2012.

3. Feng Y, Zhang F, Lokey LK, Chastain JL, Lakkis L, Eberhart D, Warren ST: Translational suppression by trinucleotide repeat expansion at FMR1. Science 1995, 268(5211):731-734.

4. Garber KB, Visootsak J, Warren ST: Fragile X syndrome. Eur J Hum Genet 2008, 16(6):666-672.

5. Huber K: Fragile $X$ syndrome: molecular mechanisms of cognitive dysfunction. Am J Psychiatry 2007, 164(4):556.

6. Jin $P$, Warren ST: New insights into fragile $X$ syndrome: from molecules to neurobehaviors. Trends Biochem Sci 2003, 28(3):152-158.

7. Santoro MR, Bray SM, Warren ST: Molecular mechanisms of fragile $X$ syndrome: a twenty-year perspective. Annu Rev Pathol 2011, 7:219-245.

8. Krueger DD, Bear MF: Toward fulfilling the promise of molecular medicine in fragile X syndrome. Annu Rev Med 2011, 62:411-429.

9. Wang T, Bray SM, Warren ST: New perspectives on the biology of fragile $X$ syndrome. Curr Opin Genet Dev 2012, 22(3):256-263.

10. Bagni $C$, Greenough WT: From mRNP trafficking to spine dysmorphogenesis: the roots of fragile $\mathrm{X}$ syndrome. Nat Rev Neurosci 2005, 6(5):376-387.

11. Bassell GJ, Warren ST: Fragile $X$ syndrome: loss of local mRNA regulation alters synaptic development and function. Neuron 2008, 60(2):201-214

12. Brown V, Small K, Lakkis L, Feng Y, Gunter C, Wilkinson KD, Warren ST: Purified recombinant Fmrp exhibits selective RNA binding as an intrinsic property of the fragile X mental retardation protein. J Biol Chem 1998, 273(25):15521-15527.

13. Costa-Mattioli M, Sossin WS, Klann E, Sonenberg N: Translational control of long-lasting synaptic plasticity and memory. Neuron 2009, 61(1):10-26.

14. Fahling M, Mrowka R, Steege A, Kirschner KM, Benko E, Forstera B, Persson PB, Thiele BJ, Meier JC, Scholz H: Translational regulation of the human achaete-scute homologue- 1 by fragile $\mathrm{X}$ mental retardation protein. J Biol Chem 2009, 284(7):4255-4266.

15. Greenough WT, Klintsova AY, Irwin SA, Galvez R, Bates KE, Weiler IJ: Synaptic regulation of protein synthesis and the fragile $\mathrm{X}$ protein. Proc Natl Acad Sci U S A 2001, 98(13):7101-7106.

16. Huber KM, Gallagher SM, Warren ST, Bear MF: Altered synaptic plasticity in a mouse model of fragile X mental retardation. Proc Natl Acad Sci U S A 2002, 99(11):7746-7750.
17. Bear MF, Huber KM, Warren ST: The mGluR theory of fragile $X$ mental retardation. Trends Neurosci 2004, 27(7):370-377.

18. Grossman AW, Aldridge GM, Weiler IJ, Greenough WT: Local protein synthesis and spine morphogenesis: Fragile $\mathrm{X}$ syndrome and beyond. J Neurosci 2006, 26(27):7151-7155

19. Kao DI, Aldridge GM, Weiler IJ, Greenough WT: Altered mRNA transport, docking, and protein translation in neurons lacking fragile $X$ mental retardation protein. Proc Natl Acad Sci U S A 2010, 107 (35):15601-15606.

20. Gross C, Berry-Kravis EM, Bassell GJ: Therapeutic strategies in fragile $X$ syndrome: dysregulated mGluR signaling and beyond. Neuropsychopharmacology 2012, 37(1):178-195.

21. Hou L, Antion MD, Hu D, Spencer CM, Paylor R, Klann E: Dynamic translational and proteasomal regulation of fragile $\mathrm{X}$ mental retardation protein controls mGluR-dependent long-term depression. Neuron 2006, 51(4):441-454.

22. Nakamoto M, Nalavadi V, Epstein MP, Narayanan U, Bassell GJ, Warren ST: Fragile $X$ mental retardation protein deficiency leads to excessive mGluR5-dependent internalization of AMPA receptors. Proc Natl Acad Sci U S A 2007, 104(39):15537-15542.

23. Osterweil EK, Krueger DD, Reinhold K, Bear MF: Hypersensitivity to mGluR5 and ERK1/2 leads to excessive protein synthesis in the hippocampus of a mouse model of fragile $X$ syndrome. J Neurosci 2010, 30(46):15616-15627

24. Richter JD, Klann E: Making synaptic plasticity and memory last: mechanisms of translational regulation. Genes Dev 2009, 23(1):1-11.

25. Wang H, Wu LJ, Kim SS, Lee FJ, Gong B, Toyoda H, Ren M, Shang YZ, Xu H, Liu F, et al: FMRP acts as a key messenger for dopamine modulation in the forebrain. Neuron 2008, 59(4):634-647.

26. Wang H, Xu H, Wu LJ, Kim SS, Chen T, Koga K, Descalzi G, Gong B, Vadakkan $\mathrm{Kl}$, Zhang $X$, et al: Identification of an adenylyl cyclase inhibitor for treating neuropathic and inflammatory pain. Sci Transl Med 2011, 3(65):65-63.

27. Zhao MG, Toyoda H, Ko SW, Ding HK, Wu LJ, Zhuo M: Deficits in trace fear memory and long-term potentiation in a mouse model for fragile $\mathrm{X}$ syndrome. J Neurosci 2005, 25(32):7385-7392.

28. Zhuo M: Molecular mechanisms of pain in the anterior cingulate cortex. $J$ Neurosci Res 2006, 84(5):927-933.

29. Zhuo M: Cortical excitation and chronic pain. Trends Neurosci 2008 , 31(4):199-207.

30. Han CJ, O'Tuathaigh CM, van Trigt L, Quinn JJ, Fanselow MS, Mongeau R, Koch C, Anderson DJ: Trace but not delay fear conditioning requires attention and the anterior cingulate cortex. Proc Natl Acad Sci U S A 2003, 100(22):13087-13092.

31. Frankland PW, Bontempi B, Talton LE, Kaczmarek L, Silva AJ: The involvement of the anterior cingulate cortex in remote contextual fear memory. Science 2004, 304(5672):881-883.

32. Hayashi ML, Rao BS, Seo JS, Choi HS, Dolan BM, Choi SY, Chattarji S, Tonegawa S: Inhibition of p21-activated kinase rescues symptoms of fragile $X$ syndrome in mice. Proc Natl Acad Sci U S A 2007, 104(27):11489-11494.

33. Tang J, Ko S, Ding HK, Qiu CS, Calejesan AA, Zhuo M: Pavlovian fear memory induced by activation in the anterior cingulate cortex. Mol Pain 2005, 1(1):6

34. Wei F, Li P, Zhuo M: Loss of synaptic depression in mammalian anterior cingulate cortex after amputation. J Neurosci 1999, 19(21):9346-9354.

35. Weiler IJ, Spangler CC, Klintsova AY, Grossman AW, Kim SH, BertainaAnglade $V$, Khaliq $H$, de Vries FE, Lambers FA, Hatia F, et al: Fragile $X$ mental retardation protein is necessary for neurotransmitter-activated protein translation at synapses. Proc Natl Acad Sci U S A 2004, 101(50):17504-17509.

36. Nosyreva ED, Huber KM: Metabotropic receptor-dependent longterm depression persists in the absence of protein synthesis in the mouse model of fragile X syndrome. J Neurophysiol 2006, 95(5):3291-3295.

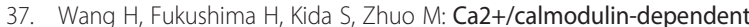
protein kinase IV links group I metabotropic glutamate receptors to fragile X mental retardation protein in cingulate cortex. J Biol Chem 2009, 284(28):18953-18962.

38. Wang H, Wu LJ, Zhang F, Zhuo M: Roles of calcium-stimulated adenylyl cyclase and calmodulin-dependent protein kinase IV in the regulation of 
FMRP by group I metabotropic glutamate receptors. J Neurosci 2008, 28(17):4385-4397.

39. Ao H, Ko SW, Zhuo M: CREB activity maintains the survival of cingulate cortical pyramidal neurons in the adult mouse brain. Mol Pain 2006, 2:15

40. Barco A, Patterson SL, Alarcon JM, Gromova P, Mata-Roig M, Morozov A, Kandel ER: Gene expression profiling of facilitated L-LTP in VP16-CREB mice reveals that BDNF is critical for the maintenance of LTP and its synaptic capture. Neuron 2005, 48(1):123-137.

41. Hardingham GE, Bading H: Synaptic versus extrasynaptic NMDA receptor signalling: implications for neurodegenerative disorders. Nat Rev Neurosci 2010, 11(10):682-696.

42. Lonze $\mathrm{BE}$, Ginty $\mathrm{DD}$ : Function and regulation of CREB family transcription factors in the nervous system. Neuron 2002, 35(4):605-623.

43. Wang H, Gong B, Vadakkan KI, Toyoda H, Kaang BK, Zhuo M: Genetic evidence for adenylyl cyclase 1 as a target for preventing neuronal excitotoxicity mediated by N-methyl-D-aspartate receptors. J Biol Chem 2007, 282(2):1507-1517.

44. Wheeler DG, Groth RD, Ma H, Barrett CF, Owen SF, Safa P, Tsien RW: $\mathrm{Ca}(\mathrm{V}) 1$ and $\mathrm{Ca}(\mathrm{V}) 2$ Channels Engage Distinct Modes of $\mathrm{Ca}(2+)$ Signaling to Control CREB-Dependent Gene Expression. Cell 2012, 149(5):1112-1124

45. WU GY, Deisseroth K, Tsien RW: Activity-dependent CREB phosphorylation: convergence of a fast, sensitive calmodulin kinase pathway and a slow, less sensitive mitogen-activated protein kinase pathway. Proc Natl Acad Sci U S A 2001, 98(5):2808-2813.

46. Du K, Asahara H, Jhala US, Wagner BL, Montminy M: Characterization of a CREB gain-of-function mutant with constitutive transcriptional activity in vivo. Mol Cell Biol 2000, 20(12):4320-4327.

47. Suzuki A, Fukushima H, Mukawa T, Toyoda H, Wu L, Zhao MG, Xu H, Shang $Y$, Endoh K, Iwamoto T, et al: Upregulation of CREB-Mediated Transcription Enhances Both Short- and Long-Term Memory. J Neurosci 2011, 31(24):8786-8802.

48. Alexander JC, McDermott CM, Tunur T, Rands V, Stelly C, Karhson D, Bowlby MR, An WF, Sweatt JD, Schrader LA: The role of calsenilin/ DREAM/KChIP3 in contextual fear conditioning. Learn Mem 2009, 16(3):167-177.

49. Gomez-Villafuertes R, Torres B, Barrio J, Savignac M, Gabellini N, Rizzato F, Pintado B, Gutierrez-Adan A, Mellstrom B, Carafoli E, et al: Downstream regulatory element antagonist modulator regulates $\mathrm{Ca} 2+$ homeostasis and viability in cerebellar neurons. J Neurosci 2005, 25(47):10822-10830.

50. Wu L, Mellstrom B, Wang H, Ren M, Domingo S, Kim SS, Li XY, Chen T, Naranjo JR, Zhuo M: DREAM (downstream regulatory element antagonist modulator) contributes to synaptic depression and contextual fear memory. Mol Brain 2010, 3:3.

51. Shaywitz AJ, Greenberg ME: CREB: a stimulus-induced transcription factor activated by a diverse array of extracellular signals. Annu Rev Biochem 1999, 68:821-861.

52. Kandel ER: The molecular biology of memory: CAMP, PKA, CRE, CREB-1, CREB-2, and CPEB. Mol Brain 2012, 5(1):14.

53. Hwu WL, Wang TR, Lee YM: FMR1 enhancer is regulated by CAMP through a CAMP-responsive element. DNA Cell Biol 1997, 16(4):449-453.

54. Smith KT, Nicholls RD, Reines D: The gene encoding the fragile X RNAbinding protein is controlled by nuclear respiratory factor 2 and the CREB family of transcription factors. Nucleic Acids Res 2006, 34(4):1205-1215.

55. Benito E, Barco A: CREB's control of intrinsic and synaptic plasticity: implications for CREB-dependent memory models. Trends Neurosci 2010 33(5):230-240

56. Ledo F, Kremer L, Mellstrom B, Naranjo JR: Ca2 +-dependent block of CREB-CBP transcription by repressor DREAM. Embo J 2002, 21(17):4583-4592.

57. Wang H, Kim SS, Zhuo M: Roles of fragile X mental retardation protein in dopaminergic stimulation-induced synapse-associated protein synthesis and subsequent alpha-amino-3-hydroxyl-5-methyl-4-isoxazole-4propionate (AMPA) receptor internalization. J Biol Chem 2010, 285(28):21888-21901.
58. Rivera-Arconada I, Benedet T, Roza C, Torres B, Barrio J, Krzyzanowska A, Avendano C, Mellstrom B, Lopez-Garcia JA, Naranjo JR: DREAM regulates BDNF-dependent spinal sensitization. Mol Pain 2010, 6:95.

59. Savignac M, Pintado B, Gutierrez-Adan A, Palczewska M, Mellstrom B, Naranjo JR: Transcriptional repressor DREAM regulates T-lymphocyte proliferation and cytokine gene expression. Embo J 2005, 24(20):3555-3564.

doi:10.1186/1756-6606-5-27

Cite this article as: Wang et al:: Roles of CREB in the regulation of FMRP by

group I metabotropic glutamate receptors

in cingulate cortex. Molecular Brain 2012 5:27.

\section{Submit your next manuscript to BioMed Central and take full advantage of:}

- Convenient online submission

- Thorough peer review

- No space constraints or color figure charges

- Immediate publication on acceptance

- Inclusion in PubMed, CAS, Scopus and Google Scholar

- Research which is freely available for redistribution 